\title{
The Capability Approach as a normative framework for technology assessment
}

\section{Capabilities in assessing digitalization in the energy transformation}

\author{
Rafaela Hillerbrand, Institute for Technology Assessment and Systems Analysis (ITAS), Karlsruhe Institute of Technology (KIT), \\ Karlstr.11, 76133 Karlsruhe (rafaela.hillerbrand@kit.edu), (1) orcid.org/0000-0002-7890-3715 \\ Christine Milchram, Department of Values, Technology \& Innovation (VTI), Faculty of Technology, Policy \& Management (TPM), \\ TU Delft (c.milchram@tudelft.nl), (1) orcid.org/0000-0002-6325-4329 \\ Jens Schippl, Institute for Technology Assessment and Systems Analysis (ITAS), Karlsruhe Institute of Technology (KIT) \\ (jens.schippl@kit.edu), (1) orcid.org/0000-0003-3169-6365
}

The digital revolution of the energy system promises a new sustainable energy future, but risks security and privacy. How to balance or at least compare these risks against other values like more sustainability is far from obvious and poses severe challenges for the orientation knowledge of technology assessment (TA). This paper explores the Capability Approach (CA) as a normative orientation for TA that allows addressing these challenges. We use two scenarios for the current digitalization in the energy sector as case studies.

\section{Der Capability Approach als normativer Ansatz für die Technikfolgenabschätzung \\ Capabilities und die Digitalisierung in der Energiewende}

Die digitale Revolution des Energiesystems verspricht eine neue nachhaltige Energiezukunft, gefährdet aber gleichzeitig Werte wie Sicherheit und Privatheit. Wie man diese Risiken gegen eine nachhaltigere Zukunft abwägen oder auch nur vergleichen kann, ist eine schwierige Frage, auf die das Orientierungswissen der Technikfolgenabschätzung (TA) eine Antwort geben muss Dieser Beitrag untersucht, was der Capability Approach (CA) als Basis eines solchen Orientierungswissens leisten kann. Dies geschieht mit Hilfe zweier Szenarien als Fallbeispiele für die Digitalisierung im Energiesektor, einem Szenario zu Smart Grids und einem zum autonomen Fahren.

Keywords: Capability Approach, energy transition, digitalization, ethics, autonomous driving

This is an article distributed under the terms of the Creative Commons Attribution License CCBY 4.0 (https://creativecommons.org/licenses/by/4.0/) https://doi.org/10.14512/tatup.28.1.52

Submitted: 13.11.2018. Peer reviewed. Accepted: 14. 02.2019
The digital revolution in the energy sector is promised to aid a transition towards a sustainable energy future (Muench et al. 2014; Fleischer and Schippl 2018). In two sectors of the energy system - electricity and transportation - digital technologies already play an important role and increase the connection and integration of the two segments. For example, smart grids promise to ensure network stability despite the growing use of intermittent wind and solar energy; smart or autonomous cars promise a reduction of emissions and immediate benefit of improved road safety. However, digitalization raises new security and privacy risks. In the energy sector, these may become particularly severe as the high dynamics of the digital era meets long-lasting electrical or mobility infrastructures (Droste-Franke et al. 2015). This increases the danger of lock-in effects as changes in the energy sector are often seen as hardly reversible.

Any technology assessment (TA) of the digitalization of the energy sector needs to address questions such as to how to weigh the value of sustainability that aggregates over generations against individualistic impacts such as privacy (Rat für Nachhaltige Entwicklung 2018). Sustainability considerations may ask to integrate more intermittent renewable energies, such as wind or solar; smart grids may be the only way to deal with the intermittency, but the data-intensive system structures come at the price of significantly lower levels in privacy. Such conflicts raise particular challenges for TA's orientation knowledge ${ }^{1}$, as it needs to square or at least compare the privacy concerns that arise on the level of individuals with the seemingly aggregated

1 TA as other problem-oriented approaches, commonly distinguish three different types of knowledge: system knowledge to better understand the causeeffects relations in a system, orientation knowledge that provides both normative orientation and future oriented reflections (scenarios), and instrumental knowledge to identify feasible and effective policy options (interventions). 
value of sustainability that aggregates over generations. In this paper, we aim to explore how the Capability Approach (CA) can provide a normative framework for TA's orientation knowledge, as the CA was suggested to provide an individualistic basis for sustainability considerations (Hillerbrand 2018).

To do so, firstly, we outline the foundations of the CA. Secondly, we demonstrate how the CA could be used in a normative assessment of technological change by analyzing two future scenarios for digitalization in the energy sector, smart grids and automated driving. We chose cases from the electricity and transport sectors as these are the ones where ICT plays the biggest role within the energy system. Our analysis is intended as an illustration how the CA puts the focus on aspects of technologies that are not addressed at all, or not centrally, either in a framework based on stated preferences or based on common sustainability considerations. It thus provides not only a new individualistic and intersubjective basis for orientation knowledge, but also asks for a different focus in the debate on the energy transition.

\section{A Capability-Framework for TA}

The CA offers a normative framework for the assessment of individual human wellbeing and of social arrangements. The basic units for assessing quality of life are the individual's 'capabilities', which refer to what a person is able to do in her life. The freedom to choose and to actively realize what one has reason to value is seen as intrinsically valuable (Sen 1992). According to the CA, a well-lived human life is a life in which central decisions are up to the person herself. Taking the CA as the basis for orientation knowledge of TA implies firstly that the individual is the central unit of evaluation. The CA thus provides an in- man well-being, it also allows us to consider alternative courses of action. This gives reversibility or rather close(st)-to-reversibility of human actions a value in itself.

There are many variants of the CA (see Leon 2017 for an overview and a more detailed account of the CA); we hold that Nussbaum's version provides a normative foundation for TA's information knowledge in a way that alleviates the tensions depicted in the first section (Hillerbrand and Goldammer 2018). Influenced by Aristotelian thinking, Nussbaum puts human dignity at the center of her account of the CA and derives the following "central human capabilities" that are indispensable for a well-lived human life (Nussbaum 2006, pp. 76-78)2:

1. Life and bodily health: the ability to live one's life to its "natural" end, which involves being able to achieve a state of good health, including adequate nourishment, reproductive health, and adequate shelter;

2. Bodily integrity: the ability to live free from oppression, e.g., to be able to move freely between places and enjoy sexual and other bodily pleasures;

3. Emotions: the ability to form attachments with things and people outside oneself;

4. Trust: the ability to build meaningful bonds with others;

5. Senses, imagination, and thought: the ability to use the senses, to imagine, think, and to reason, including the ability of scientific and artistic expression;

6. Practical reason: being able to form a conception of the good and to engage in critical reflection about the planning of one's life;

7. Affiliation: being able to connect and care about oneself (i.e., a foundation of self-respect) and others (i. e., concern for others, social engagement);

\section{The Capability Approach provides an individualistic foundation for sustainability - commonly perceived as an aggregated concept.}

dividualistic foundation for the concept of sustainability, which is commonly perceived as an aggregated concept (Hillerbrand 2018). This enables to address conflicts between, for example, issues of privacy raised by introducing smart grids, and sustainability considerations that stress the need to integrate more intermittent renewable energies such as wind or solar. Secondly, the CA answers to a central challenge inherent to sustainability considerations, i.e. the empirical inaccessibility of the preferences of future generations. It is intersubjective capabilities, i. e. what a person is able to do and be with her live, that provide the central unit of normative evaluation, not the person's preferences as in, for example, many participatory approaches to TA. participatory approaches to TA. Thirdly, with its central focus on capabilities the CA not only takes into account the impacts a certain arrangement of energy sources may have on various aspects of hu-
8. Other species: the ability to be concerned and feel connected to non-human species;

9. Play: the ability to engage in recreational activities;

10. Control over one's environment: the ability of political engagement and to claim property.

This version of the CA provides an individualist, but intersubjective value theory. It is important to note that the CA is attentive to the inevitable diversity of human beings by taking into account that individuals differ in their capacities to make use of goods and resources. At the same time, the CA assumes that capabilities can be defined in an intersubjective way. These core

2 For a critique of Nussbaum's list see Barclay 2003; Sen 2004; Crocker 2008; Robeyns 2016. 
capabilities hence are not subject to trade-offs in democratic discourse; they are non-negotiable and of intrinsic value to humans qua humans as they are seen as necessary for developing individual freedoms (e. g. Nussbaum 2006).

In the following section, we explore how the CA can be applied as a normative framework for TA. We do this by illustrating how Nussbaum's core capabilities can serve to evaluate two specific technological developments related to the digitalization in the energy sector. While TA-studies commonly consider some core capabilities such as life or bodily integrity, others may be less obvious. For example, resettlement due to climate change or lignite production as well as fears of radiation hazards impact emotions. Control over one's environment also includes being able to participate and shape essential infrastructures (see Hillerbrand and Goldammer 2018 for more details).

\section{Evaluating technological developments with a capability- theoretic approach}

For our illustrative assessment of digitalization in the energy sector using Nussbaum's core capabilities, we chose two hypothetical but plausible future scenarios for smart grids and automated driving. While there are a number of different scenarios or visions for the future of both technologies (IEA 2011, 2015; Balta-Ozkan et al. 2014; Fleischer and Schippl 2018), we focus on two scenarios that combine a high degree of digitalization with comparatively sustainable future mobility and electricity systems as in these scenarios the tensions between the aggregated level of sustainability considerations and individualistic impacts are very pronounced. Hence, we are not concerned with the likelihood of these trajectories to become reality, but more with a demonstration of how Nussbaum's core capabilities might be affected by them.

We firstly introduce smart grids and the chosen scenario. Then we highlight the scenario's impact on selected core capabilities. We follow the same structure for automated driving. In selecting several core capabilities, we concentrated on those that we think highlight most clearly aspects that are not central to other assessment frameworks such as those based on stated preferences or aggregated sustainability indicators and at the same time illustrate trade-offs between the individual and the societal level.

\section{Digitalizing electricity networks}

Smart grids such as smart metering, home energy management systems, or household batteries are seen as important enabling systems in the transition to low-carbon electricity systems (Muench et al. 2014). While facilitating the integration of solar and wind energy, smart grids raise concerns regarding, for example, consumer data privacy, security, and a loss of control to IT systems (Milchram et al. 2018 a). For our purpose, we chose the scenario "Smart 2050" developed by Balta-Ozkan et al. (2014) in which a high degree of digitalization builds on strong consumer engagement and coherent policy action.

The scenario assumes that in 2050, the United Kingdom's electricity sector has undergone a transition towards a low carbon system. The combination of top-down policy interventions and a public willingness to engage with energy issues has led to achieving targets for renewable generation and emissions reduction. Electricity is generated from a wide range of renewable sources: both offshore and onshore wind, photovoltaic systems, biomass, tidal stream and wave power; gas-fired power plants are used at peak demand and are required to be equipped with carbon capture and storage technologies; nuclear power stations and a small amount of coal-fired power stations (fitted with carbon capture and storage) provide baseload generation. Among consumers, there is broad consensus that energy systems need to change to combat climate change and that this change is largely funded by energy bills. Smart meters have been installed and the benefits become clearer as consumers begin to understand how their energy use fluctuates throughout the day. A large share of the population has grown up with in-home displays and energy management systems that are controllable via phone and computer applications. The functionalities of in-home displays have grown and there is now a market for devices that interact with household appliances. Electric vehicles and heat pumps are very common and tend to cluster (i.e. they are not evenly spread out across the country). Demand side measures including variable tariffs are widely accepted and facilitate the integration of intermittent renewables, electric vehicles, and heat pumps by shifting demand over time and reducing demand.

The following paragraphs highlight how this scenario might impact several of Nussbaum's core capabilities:

\section{Senses, imagination, and thought}

The ability to think and reason is fundamentally affected by the scenario. Consumers are enabled to reflect on how their behavior impacts energy use, supported by intelligent meters and in-home displays that allow insights into fluctuations in daily and seasonal energy use and make energy demand transparent through smartphone and computer applications.

At the same time, reasoning about their energy use depends largely on technologies that are controlled by private companies. If the transparency of prices, energy use, or the companies' use of consumers' personal and energy consumption data is hampered in any way, the ability to reason is simultaneously lessened.

\section{Trust}

Digital systems facilitate communication about pricing between energy providers and consumers and offer consumers more transparent insight into their energy use and bills. This might have a positive impact on consumers' trust in energy companies, particularly given that historically consumer trust in energy providers in the UK is very low and that this low trust is often attributed to faulty and opaque billing (Milchram et al. 2018b). 
High consumer trust, however, implies higher vulnerabilities to the misuse of digital systems. If consumer trust is exploited and consumers react by using fewer smart grid technologies and refusing to participate in demand response activities, the stability of the entire electricity network is endangered.

\section{Control over one's environment}

The transparent insight into real-time energy use for consumers not only increases consumers' ability to think and reason about their trust towards energy companies but also allows consumers greater control over their energy use. For example, in-home displays showing real-time energy prices enable consumers to use certain household appliances at times when electricity prices are with a comparatively sustainable future mobility system. A similar scenario was published in Truffer et al. (2017) and Schippl et al. (2018).

In the Scenario "Smart mobility 2050", automated vehicles enable a highly flexible mobility-on-demand system for personal transport. In urban areas, and to a lesser extent also in rural areas, personal mobility is organized via platform/smartphones, based on different, but highly integrated options such as robo-taxis, autonomous buses, trams, autonomous cars or bicycles. Autonomous vehicles are generally perceived as useful, safe and efficient. Accessibility still matters; people do not take fewer trips than before. The developments in the mobility sector co-evolved with an overarching societal paradigm of a sharing

\section{The very idea of the Capability Approach is to maximize the freedom to choose between different options.}

low. Consumers are enabled to use appliances when there is an abundance of renewable energy, and are thereby equipped with greater control over their carbon footprint.

The individualistic perspective of the CA also draws attention to the question who the individuals are that benefit. In this scenario, relatively expensive technologies like electric vehicles and heat pumps cluster geographically, most likely in areas that are more affluent. Thus, the benefits of increased autonomy and control might only be available to affluent consumers. This may also impact how the electricity grid is financed: it is publicly owned, paid for through network tariffs that are part of each electricity bill. If affluent consumer groups can reduce their dependency on - and thus their payments for - the main electricity grid, the financial burden for this public infrastructure is shifted to those consumers who are unable to afford their own electricity generation.

\section{Digitalization, automation and the future of mobility}

Automated driving has become one of the most debated topics in the transport sector within only a few years (Fleischer and Schippl 2018). Many optimistic expectations are linked in particular to self-driving cars (Skinner and Bidwell 2016; BCG 2015). These expectations include a reduction in the number of accidents, better traffic flow, more efficient usage of infrastructures, more energy efficient driving, new options for use of travel time, better mobility for disabled persons, and also competitive advantages for the automotive sector. On the other hand, there are concerns related to a common unease many people have in interacting with "robots", concerns related to safety and security, data protection and hacking, as well as an overall increase in car traffic because car usage might become more attractive (Givoni et al. 2018). For the purposes of this article, we will focus on a scenario that combines a high degree of digitalization economy. Using instead of owning is generally perceived as efficient and in a way fashionable. In the scenario, we have very low shares in private car-ownership. The vast majority of people in urban areas do not have a driver's license. In the self-driving cars and robo-taxis, it is not the users who decide about which route to take; the entire navigation is done by the platforms. Users tell the platform where they want to go and follow the instructions. This is a highly data-intensive system that comes along with a high willingness of the users to provide personal data for a good service. It is a low carbon system; motorized mobility services are based on electricity that comes mostly from renewable energies. In urban areas, public money is still used to subsidize public transport and to keep it competitive. In growing urban areas there is a strong societal and political interest in using space that was occupied by traffic to develop green and livable cities. Cities are highly appreciated as places to live and most citizens are very interested in joining opportunities for participative city development.

The scenario description already indicates how different core capabilities may be affected. While in parts this does not come as a surprise (cleaner transport leads to cleaner air and supports a healthier life, for example), some additional insights become visible and invite a more in-depth analysis. The following core capabilities are particularly illustrative:

\section{Life and bodily health}

Today's mobility solutions produce not just climate gases but also other pollutants such as NOx or noise, all of which pose a threat to human health and reduce life expectancy in European cities. It is quite obvious that the smart mobility system outlined in this scenario reduces these negative impacts of mobility on life, bodily health and bodily integrity. However, the very idea of the $\mathrm{CA}$, to maximize the freedom to choose between different options, makes us aware of another issue, namely that 
the smart mobility scenario may well lead to a lock-in situation. The ability to drive a car may be lost when driver's licenses are no longer needed and those who still have licenses do not use them. Moreover, the competencies required to organize a transportation system with thousands of individual car drivers may be lost as well. This may limit the range of future options, since such a trajectory seems hardly reversible, even when the system does no longer correspond with the preferences of future generations.

\section{Practical reason}

This category highlights the fact that mobility is a central element of daily life and key to the planning of one's own life. Therefore, crucial developments in the transport sector should be open to participation and public scrutiny. A certain degree of transparency in how the system works and performs is needed to allow for public participation and democratic control. The way the smart mobility system is governed is crucial to this aspect. A platform that integrates everything but is dominated by a single large player ("the Amazon of mobility") may efficiently provide seamless mobility services but prevent the necessary transparency and reduce citizens' influence on the further development of the system. It is imaginable that only shareholders would have a significant influence on the structure and performance of such a system. By contrast, a system based on various actors but with a public or publicly controlled institution in the driver's seat may strengthen the chances for citizens to reflect on and react to the performance of the system and to ensure a mobility system that gives them a broad scope of freedom for planning their lives..

\section{Control over one's environment}

Control over one's environment can be extended to a more general perspective on quality of life in urban areas that considers the performance of the transport system in relation to other aspects of urban design, which can be important for realizing ideas of a livable city. Taken from this perspective, cars in particular, but perhaps also other mobility infrastructures, may be perceived as a burden that reduces autonomy as regards urban development, since they consume space that could otherwise be used for other functions such as recreation or opportunities for socializing. However, ideas of what defines a "livable city" may differ between generations, and it could be argued that a well-balanced co-existence of multiple functions should allow for various activities or interests to unfold over time.

\section{Concluding discussion}

Applying the categories of the core capabilities to scenarios on smart mobility and smart grids we found that some relevant aspects are emphasized and become palpable that do not yet appear in the spotlight of TA analysis. One key issue is relevant for several core capabilities and related to the foundational idea of the CA of enabling the freedom to choose: the fundamental tension inherent in a data-intensive system that enables a high degree of flexibility and affordability in mobility and access to renewable energies for nearly everyone. On the one hand, such systems increases the possibility for individuals to choose from a broad range of mobility options and energy services, for example to make a variety of social contacts, to be given a high degree of freedom in creating personal social networks, or to benefit from lower energy prices when participating in demand response services. On the other hand, it is impossible for individuals to opt out of the data-intensive system without a massive reduction in options for mobility or without incurring the risk of paying more for one's electricity consumption. Similar lock-ins appear at the system level in both sectors. For society as a whole, the way back to a less data-intensive, rather disconnected system structure is only possible at high cost; it requires significant changes to mobility practices for individuals and to the way energy is produced, transmitted and consumed. It is then up to the democratic discourse to choose the balance between automation, privacy/security and performance. The CA is able to establish the basis for such decisions by illustrating the trade-offs and integrating both the individual and the societal level.

Our analysis further reveals that the CA does not offer a "linear metric" to assess developments in these fields. However, this is not to be expected in such complex and ambiguous contexts. The CA helps to frame useful categories for analysis and highlights issues that are highly relevant for the daily life of citizens and thus (co-)determine acceptability - but are usually underrepresented in sustainability assessment. Particularly the CA's focus on issues relevant for the individual offers an enriching perspective compared to sustainability assessment that operates mostly with aggregated indicators.

The work presented in this paper is a first attempt to illustrate the suitability of the CA to evaluate future technological developments and thus amend existing TAs. In the course of this, Nussbaum's capabilities needed to be interpreted in a way that they become context-sensitive to the digitalization of infrastructures. These interpretations are indicative and were not developed with a participatory approach. However, in Nussbaum's CA democratic considerations are needed to firstly specify the core capabilities of the relevant context; and secondly to operationalize the capabilities. Further research should also consider if and how citizen participation is useful in the context-specific interpretation of capabilities, if the CA is to comply with the democratic principles of TA. Further open questions when using the CA as normative orientation for TA concern their operationalization and aggregation as well as when and in which assessment processes the CA is to be used. The results presented in this paper illustrate that it is well worth undertaking such research, particularly as the future will confront us and those carrying out TA studies with even more intensive processes of digitalization in all fields of daily life that challenge the democratic embedding of TA and its normative ladenness. 


\section{References}

Balta-Ozkan et al. (2014): Scenarios for the development of smart grids in the UK. Synthesis report. London: UKERC.

Barclay, Linda (2003): What kind of liberal is Martha Nussbaum? In: SATS Northern European Journal of Philosophy 4 (2), pp. 5-24.

BCG - Boston Consulting Group (2015): Self-driving-vehicle features could represent a $\$ 42$ billion market by 2025. Available online at https://www.bcg. com/d/press/8jan2015-self-driving-vehicles-market-2025-832, last accessed on 10.05.2017.

Crocker, David (2008): Ethics of global development. Agency, capability, and deliberative democracy. Cambridge: Cambridge University Press.

Droste-Franke, Bert et al. (eds.) (2015): Improving energy decisions. Towards better scientific policy advice for a safe and secure future energy system. Cham: Springer.

Fleischer, Torsten; Schippl, Jens (2018): Automatisiertes Fahren. Fluch oder Segen für nachhaltige Mobilität? In: TATuP - Zeitschrift für Technikfolgenabschätzung in Theorie und Praxis 27 (2), pp. 11-15. DOI: 10.14512/tatup.28.2.11

Givoni, Moshe; Fleischer, Torsten; Schippl, Jens (2018): Interview with Prof. Moshe Givoni. Self-driving cars are completely the wrong tool for me!. In: TATUP Zeitschrift für Technikfolgenabschätzung in Theorie und Praxis 27 (2), pp. 68-71. DOI: 10.14512/tatup.27.2.68.

Hillerbrand, Rafaela (2018): Why affordable clean energy is not enough. A capability perspective on the sustainable development goals. In: Sustainability 10 (7), p. 2485. DOI: 10.3390/su10072485.

Hillerbrand, Rafaela; Goldammer, Kathrin (2018): Energy technologies and human well-being. Using sustainable design for the energy transition. In: Albrecht Fritzsche and Sascha Oks (eds.): The future of engineering. Cham: Springer, pp. 151-175.

IEA - International Energy Agency (2011): Technology roadmap smart grids. Available online at https://webstore.iea.org/technology-roadmap-smartgrids, last accessed on 16.10.2018.

IEA (2015): How 2 guide for smart grids in distribution networks roadmap development and implementation. Available online at https://webstore. iea.org/how2guide-for-smart-grids-in-distribution-networks, last accessed on 16.10.2018.

Leon, Dorian (2017): Capability approach. A formal introduction. In: Journal of Economics and Political Economy 4 (2), pp. 216-18.

Milchram, Christine; van de Kaa, Geerten; Doorn, Neelke; Künneke, Rolf (2018 a): Moral values as factors for social acceptance of smart grid technologies. In: Sustainability 10 (8), p. 2703. DOI: 10.3390/su10082703.

Milchram, Christine; Hillerbrand, Rafaela; van de Kaa, Geerten; Doorn, Neelke; Künneke, Rolf (2018 b): Energy justice and smart grid systems. Evidence from the Netherlands and the United Kingdom. In: Applied Energy 229, pp. 1244-1259. DOI: 10.1016/j.apenergy.2018.08.053.

Muench, Stefan; Thuss, Sebastian; Guenther, Edeltraut (2014): What hampers energy system transformations? The case of smart grids. In: Energy Policy 73, pp. 80-92.

Nussbaum, Martha Craven (2006): Frontiers of justice. Disability, nationality, species membership. Cambridge, MA: Belknap Press.

Rat für Nachhaltige Entwicklung (2018): Nachhaltig und digital. Nachhaltige Entwicklung als Rahmen des digitalen Wandels. Empfehlung des Rates für Nachhaltige Entwicklung an die Bundesregierung. Available online at https://www.nachhaltigkeitsrat.de/wp-content/uploads/2019/01/20181219_ RNE_Empfehlung_Digitalisierung.pdf, last accessed on 07.02.2019.
Robeyns, Ingrid (2016): Capabilitarianism. In: Journal of Human Development and Capabilities 17 (3), pp. 397-414.

Schippl, Jens; Fleischer, Torsten; Truffer, Bernhard (2018): Exploring potential impacts of societal dynamics on the development of autonomous cars. Paper presented at the $7^{\text {th }}$ Transport Research Arena TRA 2018. Vienna, Austria, 16.-19. 04.2018

Sen, Amartya (1992): Inequality reexamined. Oxford: Clarendon Press.

Sen, Amartya (2004): Capabilities, lists and public reason. In: Feminist Economics 10 (3), pp. 77-80.

Skinner, Rachel; Bidwell, Nigel (2016): Making better places. Autonomous vehicles and future opportunities. N. p.: WSP, Parsons Brinckerhoff in association with Farrells.

Truffer, Bernhard; Schippl, Jens; Fleischer, Torsten (2017): Decentering technology in technology assessment. Prospects for socio-technical transitions in electric mobility in Germany. In: Technological Forecasting and Social Change 122, pp. 34-48. D0I: 10.1016/j.techfore.2017.04.020.

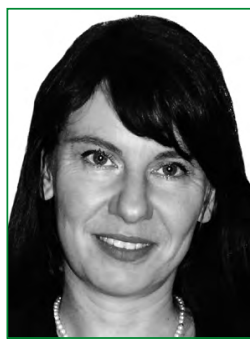

PROF. DR. DR. RAFAELA HILLERBRAND holds two doctorate degrees, one in physics and one in philosophy. Since 2015, she is professor for philosophy of engineering and technology at KIT. Her interdisciplinary research is located at the intersection between epistemology and ethics; one research focus is on how to act responsibly in the light of uncertainties and risks associated with technological progress.

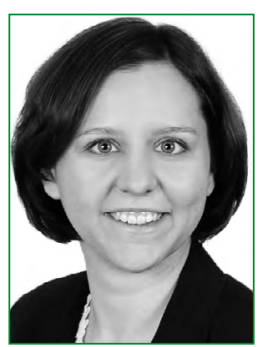

\section{CHRISTINE MILCHRAM}

has been working as a PhD researcher at the faculty of Technology, Policy and Management at Delft University of Technology (Netherlands) since 2016. Her research focuses on values and acceptability of smart grid systems, with a special interest for those systems' implications for energy justice.

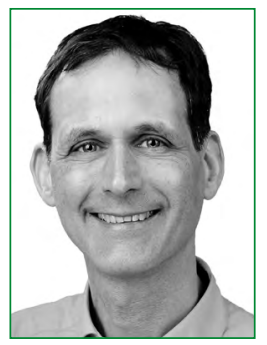

\section{JENS SCHIPPL}

studied geography, biology and of sociology at Heidelberg University. Since 2006 he works at the Institute of Technology Assessment and Systems Analysis (ITAS) at Karlsruhe Institute of Technology (KIT). His research interests encompass sociotechnical processes of change, foresight and technology assessment in the mobility sector. 